\title{
Gestational Trophoblastic Tumor pTX TNM Finding v7
}

National Cancer Institute

\section{Source}

National Cancer Institute. Gestational Trophoblastic Tumor pTX TNM Finding V7. NCI

Thesaurus. Code C89696.

Gestational trophoblastic tumor in which the primary tumor cannot be assessed. (from AJCC 7th Ed.) 